\title{
The Sustainable Development Indicators of the Environment for Cultural Landscapes in Chung Hsing New Village, Taiwan
}

\author{
Shih-Jen Feng and I-Hui Lin
}

\begin{abstract}
Chung Hsing New Village was built up to ease administrative issues and air defense relocate scheme by the government in 1956. It covers up to 252 hectares by national land and aims to in charge of the essential works of counties, cities and towns of the province. Furthermore, it was the pioneer of urban planning concerned with the development, design of land use and the built environment in Taiwan. Chung Hsing New Village took the case study from Ebenezer Howard's Garden City, included connecting the suburbanization development with compact layouts, low-density development with good public spaces and emphasis on neighborhood unit in the thoughts, to create a functional working environment and public facility as a model of town planning in Taiwan. However, due to the downsizing of the Taiwan provincial government in 1998, most administrative workers were laid off, and yet, the Jiji earthquake damaged lots of buildings in 1999. Despite this, the remarkable value of culture and advanced concept of town planning made Chung Hsing New Village had been listed as cultural landscapes preservation since 12th April 2011, but compare to the other countries' regulation of cultural landscapes and sustainable environmental preservation framework, the authorities failed to act and lack of big picture caused severe problems like abandoned and ruined, etc. To sum up, this research aims to explore the core value of Chung Hsing New Village environmentally sustainable, follow up with literature review, field investigate and in-depth interview with experts to construct Chung Hsing New Village cultural landscapes. The sustainable development indicators and the weight analysis of analytic hierarchy Process (AHP). Comparing the two results, it demonstrates the value of sustainable development indicators and contributes to the following cohort study of Chung Hsing New Village.
\end{abstract}

Index Terms - Chung Hsing New Village, cultural landscape, sustainable development.

\section{INTRODUCTION}

As was pointed out in the introduction to this paper, during 50 years after Taiwanese government relocated to Chung Hsing New Village, the government consistent the spirit of Chung Hsing to manage the essential works from nationwide, such as press ahead modernisation toward the affluent society. In the era of poor livelihoods, the scale of development of Chung Hsing New Village is extraordinary, in a perspective view of the urban plan, took a lesson from the first generation

Manuscript received October 12, 2020; revised March 12, 2021.

Shih-Jen Feng is with the Department of Architecture, Chaoyang University of Technology, Taichung 41349, Taiwan (e-mail: fengshyhren@yahoo.com.tw).

I-Hui Lin was with Department and Graduate Institute of Architecture, Chaoyang University of Technology, Taichung 41349, Taiwan (e-mail: aaron@cyut.edu.tw). of new town plan in England, Chung Hsing New Village contains a vision to impact and long term plan. According to Ebenezer Hawar's theory - Garden City in 1898, the idealist community should connect work and family, aesthetic and self-sufficient for rural urbanization. Regarding this, the governor of Taiwan Province $\mathrm{Mr}$ Tung-Min Hsieh's authorised to took Garden City (England) as an example to improve the rundown rural area a new vision, and Chung Hsing New Village was born; however, Chung Hsing New Village is where everything began, planning meticulously with blueprints, then build up from blueprints, for this urban planning division, the office building and sewage disposal was all designed from the progressive theories. Besides, owing to downsizing the Taiwan provincial government in 1998 and Jiji earthquake damaged lots of buildings in 1999, the year comes after with typhoon brought bullet rains which gradually destroyed houses and environmental resources, furthermore, lack of environmentally sustainable development and inaccurate mended system from the competent authority, resulting in the characteristic landscape context disappeared, therefore, this research aims to propose an environmental sustainable development indicators for competent authority and cohort study.

\section{LITERATURE REVIEW}

\section{A. Cultural Landscapes Value Determination}

The purpose of this chapter is to review the literature on Cultural Landscapes Value Determination. It begins by the value of cultural landscapes following the historic development, the indigenous culture and interaction from natural in context [1]. The vital formation of cultural landscapes could be the witness of local economic, cultural development and any cultural landscapes could be different due to the human being needs and environmentally features [2], in contrast with other cultural heritage value, the difference is cultural landscapes base on the historical value, building technical and material value of tangible heritage, as explained earlier, emphasize domestic lifestyle from locals oral history interviews, social community and environmentally sustainable development is considerable for cultural landscape [3]. According to the literature review of cultural landscapes value, this chapter summaries 8 values of preservation:

\section{B. Cultural Landscape Preservation Strategy}

The purpose of this chapter is to review the literature on cultural landscapes preservation. It begins by the 
preservation of cultural landscape which based on dedicate survey and evaluation of the site within the protection, maintenance, restoration and reconstruction instructions follows the principle of authenticity and integrity, moreover, focusing preservation procedure and outcome on the culture and natural features involve spatial processes, land use, topography, hydrology, vegetation, transportation, detail structure, decoration, health and environment, in addition, local food, clothes style, building pattern, transportation, education and entertainments etc. are the main elements to link locals memory and space together to shapes fascination.

Mike Crang (1998) believes that the patterns of interaction, behaviours what people learned from daily life are being considered for granted. To explore more about what those patterns, he suggested that the experience of living in the site, went for vacation and field trip could benefit for further investigation.

TABLE I: CULTURAL LANDSCAPES PRESERVATION VALUE ANALYSIS

\begin{tabular}{ll}
\hline \hline Value & Summary \\
\hline Symbolic & $\begin{array}{l}\text { Mostly in the era or process of evolution, tangible } \\
\text { substances, both representative and strong characteristics. }\end{array}$ \\
\hline Aesthetics & $\begin{array}{l}\text { Commonly confused by the historic and cultural value, } \\
\text { within a specific spatial or environment atmosphere to } \\
\text { distinguish the value between historic and aesthetics. }\end{array}$ \\
\hline Economic & $\begin{array}{l}\text { Through economic redevelopment, human behaviors can } \\
\text { be brought in with modern economic value for preserved } \\
\text { and regenerated. }\end{array}$ \\
\hline Historic and & $\begin{array}{l}\text { Complete historic data can provide direct evidence for the } \\
\text { cohort study. } \\
\text { Carry on with the historic and cultural value through the } \\
\text { exploration progress of textual research and significance of } \\
\text { inheritance. }\end{array}$ \\
\hline Remarkable & $\begin{array}{l}\text { Non-renewable and difficult to reproduce, mostly related to } \\
\text { specific local cultural characteristics. }\end{array}$ \\
\hline Spiritual & $\begin{array}{l}\text { Sharing the same cultural and living background, such as } \\
\text { religion, customs, or working together. }\end{array}$ \\
\hline Sustainable & $\begin{array}{l}\text { Cultural landscapes are mostly superposition by time and } \\
\text { continuedly evolve. }\end{array}$ \\
\hline Society & $\begin{array}{l}\text { Having a direct connection relationship in society and } \\
\text { cultural interaction. }\end{array}$ \\
\hline \hline
\end{tabular}

According to the manual published by English Heritage, every preservation area has a feature based on topography, history, economic development, status. Furthermore, surroundings, open space of the site, antique, the name of the building and the place also relates [4]. In order understanding and evaluate it, we must know the background of society and economy trend of the site, the theory that the urban morphosis. Therefore, this research could be a very important foundation for the cohort study on development and management.

\section{Environmental Sustainable Development}

In terms of "Sustainable development" was initially used by The International Union for Conservation of Nature(IUCN), United Nations Environment Programme (UNEP) and World Wild Fund for Nature(WWF) international conservation organizations in 1980, According to the "World Conservation Strategy" report. Recently, the most widely used and officially adopted definition of sustainable development in the report from "World
Commission on Environment and Development - Our Common Future" in 1987. Quote from WCED "development that meets the needs of the present without compromising the ability of future generations to meet their own needs." It mainly includes natural resources and ecological environment, economy and society, based on the sustainable use of natural resources and benefit of ecological environment, under the premise with the sustainable ecological environment, and seek the overall progress of society as a goal, coordination these three developments can be the requirements of sustainable development.

This chapter aims to discuss the environmentally sustainable development of Chung Hsing New Village. environmentally sustainable development is the interaction of human, biological and environmental. That is to say, through the integration of "ecological sustainability" and "economic development", through the effective use of natural resources, regional human carrying capacity and recycling of by-products, we can find out our own economic model, rather than maintain an ideal static state. The indicators should include the characteristic of landscape, historic humanities and natural ecology of Chung Hsing New Village, and retain the historical memory related to the life on the ground, maintain a certain level of economic activities and quality of life [5], and these indicators can be important criteria for the environmental sustainable development.

\section{RESEARCH METHODS}

Having discussed how to construct the indicators of Environmental Sustainable Development, this section will address Research Methods from the literature review, experts and scholars interviews and local elderly oral history to construct the assessment of environmentally sustainable development of Chung Hsing New Village cultural landscape. As regards of AHP statistical analysis, these indicators outweigh its relationship, in order to benefit the cohort study of the village environment sustainable development and development assessment, it is essential to establish indicators as reference.

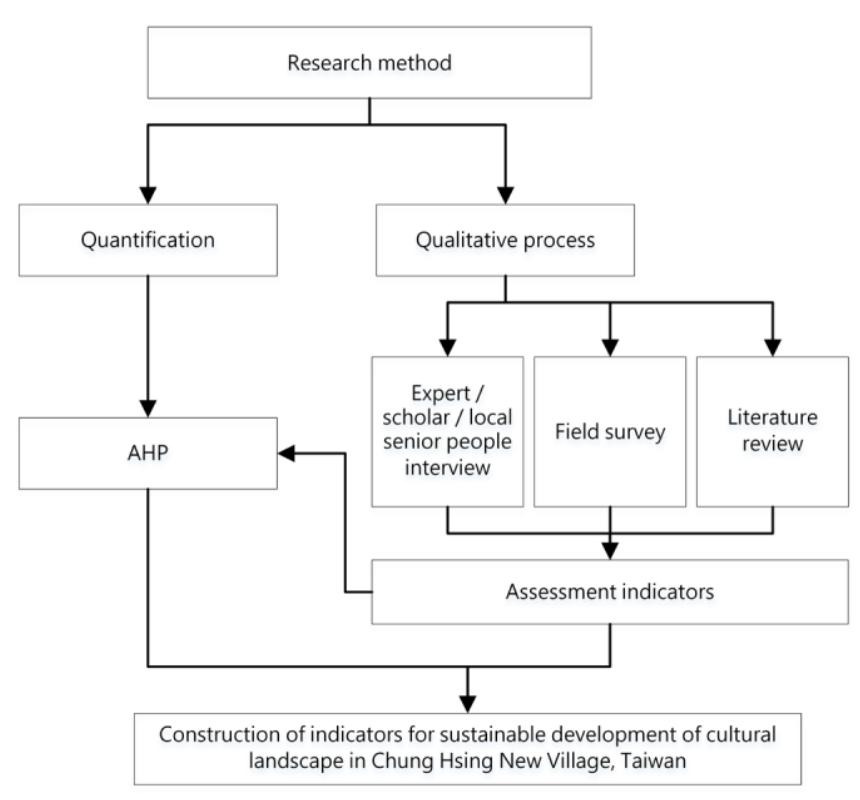

Fig. 1. Research methods workflow. 


\section{Chung Hsing New Village Cultural Landscapes} ENVIRONMENTALLY SUSTAINABLE VALUE IN THE CONTEXT

\section{A. Urban Planning Environment}

This chapter is divided into three parts. The first is the contexts of urban planning environment, following with landscape ecological environment and humanities of architectural environment.

As far as Urban Planning Environment is concerned in Chung Hsing New Village's, the urban planning division of the history of Taiwan Urban history published its first urban planning area with the concept of "Garden City", it's contained the features of "New Towns Movement" and "Neighborhood Unit", in order to correspondence the distribution of administrative districts [6], residential areas and town centres, etc. In addition, the introduction of advanced urbanization equipment, so that life could be more convenient, amenity, self-sufficient, balance the living demand in Chung Hsing New Village.

As discussed above, Chung Hsing New Village is a crucial administrative district of Taiwan Provincial Government, moreover, as a great practice of advanced urban district under the urban plan, and ideal Utopia living environment for Taiwan's Urban Development. Additionally, it also has a well-educated and teaching space of architectural history, landscape ecology and aesthetic value in Taiwan.

Context: Garden Cities, New Towns Movement, Neighborhood Unit, Intensity of Land Use, Transportation System, Systematic Foundation, Air Defence Scheme, etc.
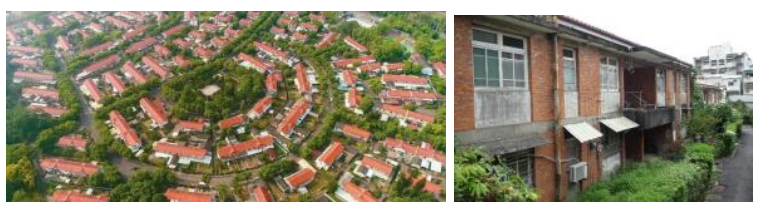

\section{B. Landscape Ecological Environment}

As explained earlier, Chung Hsing New Village was planned to build aside Hushan mountain which the barrier from natural, The buildings are mainly concentrated in the lower slope of the foot of the mountain area, showing the Longitude configuration of north and south. Most of the rivers run through the building's Community from east to west, forming the physical geography of Chung Hsing New Village [7]. The land of using in Chung Hsing New Village occupies high parkland, wide-area lawn swathes of the area and tree-lined views along the road is the most impressive landscape feature of tourists. Besides, regional administrative districts, residential district and public facilities, the vast open space of its building is completely afforestation [8]. Chung Hsing New Village makes people getting spiritual relief with green belt delightful.

Context: Natural Landscape of Mountain Scenario, Landscape Ecology, Riverscape, Green Belt and Tree Boulevard, Green Space, Precious Old Trees, etc.
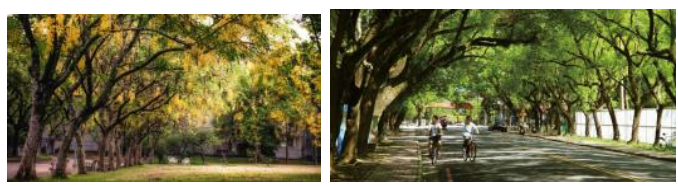

\section{Architectural Humanities Environment}

In terms of Architectural humanities environment, while Taiwan Provincial Government relocated to Chung Hsing New Village, the government urgent to build a new type of community and estimates the air defence scheme, the density of residential buildings in neighbourhood units should be as low as possible and appropriate green space should be retained [9]. The present building type in the Chung Hsing New Village is mostly for residential. The building type is mainly apartment complex type and residential type, apartment complex type is mostly office-based, residential type roughly divided into bungalow and cottage [10]. Each architectural represents the design thinking, cultural literacy, theory, stylish and details from architects, delivered modern aesthetics and culturalism of architecture [11].

The remarkable value of Chung Hsing New Village, by profound tangible heritage and intangible heritage, represented by the landscape of the past provincial capital. On the other hand, Chung Hsing New Village residents from the original exclusion to the spirit of home support. From barren land to the space atmosphere of witnessing history, the value of provincial life culture including Symbolic spatial composition, planting, building configuration, advanced urban functions and public facilities, etc. All kinds of evolution and development are the residents' living course and memory. It does not only succeed by shaping the model, as back to the early days of planning, completion within such a short term and the complex frame is also more dedicated of the efficiency and foresight of the provincial government in implementing its policies.

Context: Evacuation Office, Public Engineering Bureau of National Housing Office, Demolition Committee Engineering Office, Temporary Engineering Office of the Construction Department, the first post-war generation of well-known architects, office buildings of the provincial government, staff dormitories of the provincial government, public facilities, etc.
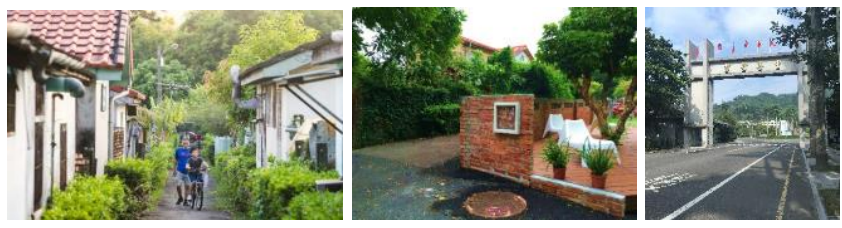

\section{The Sustainable DEVElopment IndicAtors OF Chung Hsing New Villag Cultural LandscaPe}

\section{A. The Sustainable Development Indicators Establish}

In the section that follows, through literature review and research methods, this research intents to obtain the environmentally sustainable indicators from the Urban Planning Division, Landscape ecological environment and architectural humanities environment factors of Chung Hsing New Village. The details of 9 environmental sustainability indicators as below:

\section{1) Urban planning division}

- Traffic systems planning: There are many positive reasons for separate pedestrian from traffic and divided 
the road into different levels of planning. Furthermore, cul-de-sac road and horseshoe-shaped ring road texture are significantly utilized to reduce the speed of vehicles. As has been said, the idea of separated pedestrians from traffic and the block design provides a completely pedestrian footpath system.

- Neighbourhood Unit: The basic element of the urban environment is distinguishing from living hood standard and spatial form of environment. The residential district is organised with elementary school, park and market as the neighbourhood unit mode centre, while the cul-de-sac road space becoming co-living public space of residents and has characteristics of administrative and office space.

- Separated Sewerage System: In this case, the sewer system separate sewage sewers and storm sewers to collect sewage and rainwater as known as separate sewerage system. The master planning shows a complete urban sewage management system and the primary domestic sewage treatment plant with an independent water supply system. To collect the water from the side ditch of the mountain flowing in the direction of the Hushan mountain are utilized to lead the culvert pipe to the west side of the Huangshan Road, and three enormous drainage ditches are prepare for ease the rainfall.

\section{2) Landscape ecological environment}

- Green space: The definition of green space in Chung Hsing New Village is collaborate from park, playground and green space etc., connected with public footpath. The land use in Chung Hsing New Village mainly occupied by park and afforestation with surrounding open spaces, so that Chung Hsing New Village becomes a full of afforestation of suburban town impact. The advantage is to tackle the plan of garden city and provide administrative staff, independents and tourists a leisure space.

- Boulevard: The ecological and drainage system of Chung Hsing New Village is affluent of the Hushan mountains, has reached the early stage of large-scale environmental afforestation, including bushes and trees. Nowadays, Chung Hsing New Village is rich in environmental landscape ecosystem for ecological connected benefits, and the boulevard composed of main roads has become a valuable vegetation feature in Chung Hsing New Village, which is also regarded as the unrecoverable plant ecological resources.

- Hydrologic system: At present, the main rivers in Chung Hsing New Village, include Neilun River, Jungong River and vertical and horizontal agricultural irrigation channels. Among them, most of the ditches run through the building tribe of the east-west direction, interaction with varies landscape resources, shaping the physical geography of Chung Hsing New Village.

\section{3) Architectural humanities}

- Low density residential: Due to the planning feature of urban ruralisation and rural urbanisation, most of the buildings are low built and low bulk in Chung Hsing New Village, but exceptional purpose. Therefore, the green space and the number of public spaces is reserved.

- Residential Plan:For the rightful privacy and functions aspect, the house plan links kitchens and garages as service spaces to connect cul-de-sac and intended to categories the living rooms and bedrooms with a unique view of green spaces and gardens.

- Lifestyle of locals:Chung Hsing New Village was transferred from civil servant Military Dependents' Village, shaping a village with special provincial culture. In the early years, it substitutes abundant intermediary like cultural exchanges such as eating habit, marriage, cultural custom, etc.

\section{B. Weight Analysis of Sustainable Development Indicators}

Having discussed how to construct environmentally sustainable value, the final section of this chapter addresses ways of the interview of expert questionnaires, and through the AHP statistical analysis, as regards the distribution of questionnaire from industry, officials, academic experts, the criteria require environmental sustainable, ecological restoration, and landscape environmental planning of the relevant academic knowledge, in consideration of 16 questionnaires and 2 invalid questionnaires of 18 questionnaires. The weight analysis of sustainable development indicators as chart below:

\begin{tabular}{|c|c|c|c|c|c|}
\hline atures & $\begin{array}{l}\text { Assess } \\
\text { Indicators }\end{array}$ & $\begin{array}{l}\text { Relative } \\
\text { Weight }\end{array}$ & $\begin{array}{l}\text { Relativ } \\
\text { e Order }\end{array}$ & $\begin{array}{l}\text { Absolute } \\
\text { Weight }\end{array}$ & $\begin{array}{l}\text { Absolut } \\
\text { e Order }\end{array}$ \\
\hline \multirow{3}{*}{$\begin{array}{l}\text { rban } \\
\text { anning } \\
\text { ivision } \\
.3634)\end{array}$} & $\begin{array}{l}\text { Transportat } \\
\text { ion System }\end{array}$ & 0.3487 & 6 & 0.1267 & 4 \\
\hline & $\begin{array}{l}\text { Neighbourh } \\
\text { ood Unit }\end{array}$ & 0.4141 & 2 & 0.1505 & 2 \\
\hline & $\begin{array}{l}\text { Separated } \\
\text { Sewerage } \\
\text { System }\end{array}$ & 0.2372 & 8 & 0.0862 & 7 \\
\hline \multirow{3}{*}{$\begin{array}{l}\text { andscape } \\
\text { cological } \\
\text { hvironment } \\
.3980 \text { ) }\end{array}$} & Green space & 0.3580 & 5 & 0.1425 & 3 \\
\hline & Boulevard & 0.4354 & 1 & 0.1733 & 1 \\
\hline & $\begin{array}{l}\text { Hydrologic } \\
\text { system }\end{array}$ & 0.2065 & 9 & 0.0822 & 8 \\
\hline \multirow{3}{*}{$\begin{array}{l}\text { rchitectural } \\
\text { Imanities } \\
.2386)\end{array}$} & $\begin{array}{l}\text { Low } \\
\text { density } \\
\text { residential }\end{array}$ & 0.3671 & 4 & 0.0876 & 6 \\
\hline & $\begin{array}{l}\text { Residential } \\
\text { Plan }\end{array}$ & 0.2624 & 7 & 0.0626 & 9 \\
\hline & $\begin{array}{l}\text { Lifestyle of } \\
\text { locals }\end{array}$ & 0.3705 & 3 & 0.0884 & 5 \\
\hline
\end{tabular}

\section{CONCLUSION}

From the previous discussion, it shows that the World Heritage is facing its majority challenge of in urban plan and city economic development. The development of pursuing economic growth for a long time leads to the destruction of environmentally sustainable development, for instance, various environmental issues long swept under the carpet came to the fore. The public realizes that economic development by the environmental capacity constraints and the issue of sustainable development of the environment gradually. Therefore, the sustainable development of cultural asset space, in addition to maintaining the unique land landscape, historical culture and natural ecology, preserving the historical memory related to life on the ground, and we should integrate "ecological sustainability" and "economic development" to find out our economic model, rather than maintaining an ideal st0atic state. 
Likewise, the cultural landscapes of Chung Hsing New Village in Taiwan were initially built for political considerations. It was composed of civil servant Military Dependents' Village from mainland china. After the glorious period of the provincial government, it witnessed the important historical, political, economic, social and cultural development process of Taiwan. Its values the special cultural atmosphere and complete urban planning also in the cultural value of permanence or continuity of its overall environment. The environmentally sustainable development needs the participation of government, civil, community and individual. For the construction of the sustainable development indicators of the environment for cultural landscapes in Chung Hsing New Village, the interactive relationship of both human and the environment as a benchmark, construct nine environmental sustainability indicators. The following is a brief report on analysis and statistics, we can see that "landscape ecological environment" will be the most important way to preserve the cultural landscapes in the future. However, we should adjust the function and intensity of urban land use based on the principle of maintenance and reflect from use of the subsequent entry units. For the systematic urban equipment, the statistics show the maintains needs of its presence of historic value and through preservation indicator to restore the authentic form and function.

In Conclusion, the purpose of this study aims to preserve the remarkable landscape texture of Chung Hsing New Village in Taiwan and provide a reference for competent authority and cohort study, and to enhance its economic motivation and social influence. Moreover, this research recommended that the cohort study can improve the structural integrity in combination with different research methods, to improve the future environmental in Chung Hsing New Village with indicators mitigation.

\section{CONFLICTS OF INTEREST}

The authors declare no conflict of interest.

\section{AUTHOR CONTRIBUTIONS}

Supervision, S.-J.F.; Writing - original draft, S.-J.F.;
Writing - review \& editing, S.-J. F. \& I.-H. L.

\section{REFERENCES}

[1] T.-H. Tai and K.-Y. Tai, The Reappearance of Historical and Cultural Landscape, Chain: Tongji University Press, p. 13, 2009.

[2] N.-H. Chou, K.-C. Yu, and C.-F. Huang, "Paying attention to the new trend of heritage protection: cultural landscape," Human Geography, vol. 5, 2006,

[3] C.-C. Liu, Settlement and Cultural Landscape Preservation Operation Execution Manual, Taichung: Bureau of Cultural Heritage, Ministry of Culture Press, 2012.

[4] H. So, Landscape Transformation of Chinguashi Mining Town: Referring to the Norwegian Method of Describing Landscape, in Cultural Landscapes as Cultural Heritage: Conservation Philosophy and Management Method through comparing Norway and Taiwan, 2007.

[5] C.-J. Hsia, Theoretical Architecture - Theoretical Construction towards Spatial Practice, Taipei: Taiwan: A Radical Quarterly in Social Studies Press, 1992.

[6] National Science Council, Chung Hsing New Village Advanced Research Park Project, 2009.

[7] Central Taiwan Science Park, Ministry of Science and Technology, Chung Hsing New Village Advanced Research Park Cultural Heritage Preservation Project, 2011.

[8] M.-C. Yang, "Chung Hsing New Village cultural landscape preservation and maintenance project and research project," Cultural Affairs Bureau of Nantou County, 2015.

[9] C.-D. Chung, Nantou County Cultural landscape Chung Hsing New Village Oral History Research Project, Cultural Affairs Bureau of Nantou County, 2014.

[10] Y.-C. Li, Chung Hsing New Village Cultural Heritage Evaluation Survey Project, Cultural Affairs Bureau of Nantou County, 2010.

[11] S.-J. Feng, Chung Hsing New Village Cultural landscape Reconstruction Historical Site Project, Cultural Affairs Bureau of Nantou County, 2017.

Copyright $(92021$ by the authors. This is an open access article distributed under the Creative Commons Attribution License which permits unrestricted use, distribution, and reproduction in any medium, provided the original work is properly cited (CC BY 4.0).

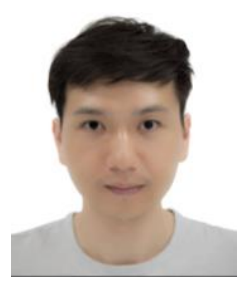

Shih-Jen Feng is an assistant professor at the Chaoyang University of Technology, Department of Architecture, in Taichung, Taiwan. His expertise is architectural design, cultural industrial heritage, urban design and planning. 